\title{
Human immunodeficiency virus in injecting drug users in Europe following a reported increase of cases in Greece and Romania, 2011
}

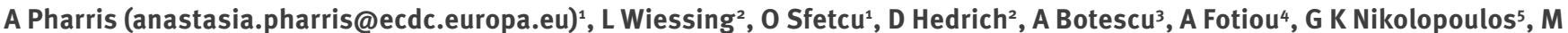
Malliori ${ }^{6}$, M Salminen ${ }^{1}$, J E Suk ${ }^{1}$, P Griffith ${ }^{2}$, M J van de Laar ${ }^{1}$

1. European Centre for Disease Prevention and Control (ECDC), Stockholm, Sweden

2. European Monitoring Centre for Drugs and Drug Addiction (EMCDDA), Lisbon, Portugal

3. National Observatory on Drugs, National Anti-Drug Agency, Bucharest, Romania

4. National Focal Point of the EMCDDA, University Mental Health Research Institute, Athens, Greece

5. Hellenic Centre for Disease Control and Prevention, Athens, Greece

6. Organisation Against Drugs (OKANA), Athens, Greece

Pharris A, Wiessing L, Sfetcu O, Hedrich D, Botescu A, Fotiou A, Nikolopoulos GK, Malliori M, Salminen M, Suk JE, Griffiths P, van de Laar MJ. Human immunodeficiency virus in injecting drug users in Europe following a reported increase of cases in Greece and Romania, 2011.

Euro Surveill. 2011;16(48):pii=20032. Available online: http://www.eurosurveillance.org/ViewArticle.aspx?Articleld=20032

Article published on 1 December 2011

Greece and Romania reported an increased number of HIV cases among injecting drug users (IDUs) during 2011. Most European countries reported no changes in the rate of newly diagnosed cases of HIV or HIV prevalence in IDUs; however, six countries did report increases and several additional countries reported increases in injecting risk indicators or low coverage of prevention services. These indicate a potential risk for increased HIV transmission and future outbreaks unless adequate prevention is implemented.

In 2010, the number of newly diagnosed human immunodeficiency virus (HIV) cases among injecting drug users (IDUs) represent only $4 \%$ of the total number of reported HIV cases in the European Union (EU) [1]. However, increases in HIV infections among IDUs in Greece were reported in July 2011, through the European Monitoring Centre for Drugs and Drug Addiction (EMCDDA), followed by a reported increase in Romania in November 2011. Preliminary results of the investigation on the Greek outbreak were released in September [2] and November 2011, respectively [3]. These subsequently led to a request from the European Commission to carry out a rapid risk assessment at EU level.

\section{Epidemiological situation of \\ HIV in Greece in 2011}

Since the beginning of 2011, the number of newly diagnosed HIV infections has increased among IDUs in Greece. Between nine and 16 cases were reported annually among IDUs during 2006-2010, representing $2-3 \%$ of the total newly diagnosed HIV infections, while during the first 10 months of 2011, cases among IDUs sharply increased to 190, representing approximately $25 \%$ of all reported HIV cases [2,3]. Prevalence studies have also detected a steep increase of HIV among IDUs in 2011, mostly in Athens [3].

Prior to the 2011 outbreak, the coverage of prevention services was low, with waiting times for opioid substitution treatment estimated at 89 months in 2010 and with an estimated distribution of only six sterile syringes per IDU during the entire year of 2009, which is far lower than in most European countries that report data to calculate syringe distribution per IDU [4]. In response to the outbreak, the Greek authorities have sought to rapidly expand opioid substitution treatment services and have started mobile prevention services offering information, voluntary testing, referrals and clean needles and syringes [3].

\section{Epidemiological situation of HIV in Romania in 2011}

In November 2011, a strong increase of newly diagnosed HIV infections among IDUs during 2011 was reported to EMCDDA based on the information provided by routine monitoring and case reporting coordinated by the Romanian Ministry of Health. While reporting three to five cases annually from 2007 to 2009, HIV infections among IDUs increased to 12 cases in 2010 and to 62 cases in the first nine months of 2011 . Routine monitoring performed at registration for drug treatment services indicated an increase in HIV positive cases among IDUs tested (1.1\% (2/182) in 2008, 3.3\% (11/329) in 2009 and $4.2 \%(12 / 288)$ in 2010). Cases reported in 2011 were mostly residents of Bucharest and the surrounding area (56/62), predominately males (55/62), and younger than 34 years (55/62). Twenty-nine cases had confirmed $C D$ cell counts at diagnosis higher than 500 cells $/ \mathrm{mm}^{3}$ suggesting recently acquired HIV infections. No specific HIV testing campaigns had been initi- 
ated and most cases were detected when seeking drug treatment or hospital care for other conditions.

In behavioural surveillance surveys among IDUs, there are reports of changes in drug use patterns from 2009, where $97 \%$ of respondents reported heroin as the main drug of injection, to 2010 , where $67 \%$ reported heroin and $31 \%$ reported amphetamine-type stimulants, mostly synthetic cathinones, as the main drug of injection. Stimulant use is associated with more frequent injection and there are reports of increased syringesharing [5].

While drug use and injection risk patterns appear to be changing in Romania, access to sterile syringes has decreased. Numbers of sterile syringes distributed reportedly declined from 1.7 million in 2009 to 965,203 in 2010 and to approximately 700,000 up to November 2011. Based on the estimated number of IDUs, syringe provision in Bucharest has thus decreased from 97 syringes per IDU in 2009 to 53 syringes in 2010. While the overall provision of opioid substitution treatment in Romania seems to be limited, the number of clients in such programmes increased from 424 in 2009 to 601 in $2010[6,7]$.

\section{Background}

HIV infection is one of the most serious potential health consequences associated with IDU, leading to chronic infection, acquired immunodeficiency syndrome (AIDS) and premature death if untreated [1]. In the EU and the European Economic Area (EEA), the estimated HIV prevalence rates among IDUs range from less than $1 \%$ to more than $60 \%[8,9]$. Although for the EU/EEA area as a whole the number of new HIV diagnoses reported annually among IDUs has declined by $44 \%$ since 2004 , outbreaks have been observed within a number of countries in recent years [9-13].
The risk for blood-borne virus infection outbreaks among IDUs depends on multiple factors, including the frequency of needle sharing, the number of needle sharing partners, the social network structures and mixing in the IDU population. Additional determinants include the size of the IDU population, the types of drugs injected, exposure through commercial sex and other risky sexual practices, and awareness of risks and prevention measures available. In a more general perspective, public health and drug policies as well as the legal environment can also determine infection risks [14].

\section{Assessment of the situation of human immunodeficiency virus among injecting drug users in the European Union/ European Economic Area}

In response to the notified events in Greece and Romania, the European Centre for Disease Prevention and Control (ECDC) and the EMCDDA conducted a rapid inquiry to HIV surveillance contact points and national drug focal points in the EU/EEA Member States, candidate and potential candidate countries, in November 2011, to investigate possible recent increases in HIV infections detected among IDUs. Information available from routine surveillance and monitoring of HIV and hepatitis $\mathrm{C}(\mathrm{HCV})$ as well as prevention coverage among IDUs has been combined with results from the rapid inquiry (Table).

Increases in HIV case reports or prevalence among IDUs were reported by six countries as compared to 2008-2010. Seventeen countries reported no changes, four reported fewer cases or lower prevalence, and two did not have information available to assess a change. Countries reporting an increase in the most recent year from which data were available (2011 or 2010) were Bulgaria, Greece, Italy, Lithuania, Luxembourg, and Romania.

\section{TABLE}

Indicators of human immunodeficiency virus and hepatitis $\mathrm{C}$ virus transmission, injecting risk and intervention coverage, European Union and European Economic Area, 2008-2011

\begin{tabular}{|c|c|c|c|c|c|c|c|c|}
\hline EU/EEA country & $\begin{array}{l}\text { Increase in } \\
\text { the number of } \\
\text { HIV cases }\end{array}$ & $\begin{array}{l}\text { HIV } \\
\text { prevalence } \\
\text { increase }\end{array}$ & $\begin{array}{l}\text { Hepatitis C } \\
\text { prevalence } \\
\text { increase }\end{array}$ & $\begin{array}{c}\text { Other } \\
\text { injecting risk } \\
\text { increase }\end{array}$ & $\begin{array}{l}\text { Injection } \\
\text { drug use } \\
\text { prevalence } \\
\text { increase }\end{array}$ & $\begin{array}{l}\text { Less than } \\
30 \% \text { of } \\
\text { problem } \\
\text { opioid users } \\
\text { in opioid } \\
\text { substitution } \\
\text { treatment }^{2}\end{array}$ & $\begin{array}{l}\text { Less than } \\
100 \text { syringes } \\
\text { per IDU per } \\
\text { year from } \\
\text { specialised } \\
\text { programmes }^{3}\end{array}$ & $\begin{array}{c}\text { Surveillance } \\
\text { changes }\end{array}$ \\
\hline Austria & 2010 & 2010 & $2010^{4}$ & 5 & & $52 \%$ & & \\
\hline Belgium & 2010 & 2010 & 2010 & & & & & \\
\hline Bulgaria & 2009 & $2010^{6}$ & $2010^{7}$ & 8 & & & & \\
\hline Croatia & 2010 & & & & 9 & & 89 & \\
\hline Cyprus & 2010 & $2010^{10}$ & $2010^{11}$ & & 9 & $27 \%$ in 2010 & 0 & \\
\hline Czech Republic & 2010 & 2010 & & & 9 & $32 \%$ & 138 & \\
\hline Denmark & 2010 & & 2008 & & & & & \\
\hline Estonia & 2010 & & & & & & 164 & \\
\hline Finland & 2010 & 2009 & 2009 & & & $32 \%$ & & \\
\hline
\end{tabular}




\begin{tabular}{|c|c|c|c|c|c|c|c|c|}
\hline France & 2010 & & & & & & & \\
\hline Germany & 2010 & & & & & $55 \%$ & & \\
\hline Greece & 2011 & $2011^{12}$ & $2010^{13}$ & 14 & 9 & $22 \%$ in 2010 & 6 & \\
\hline Hungary & 2010 & $2010^{15}$ & & 5,8 & 16 & $32 \%$ & 69 & \\
\hline Iceland & 2010 & & & & & & & \\
\hline Ireland & 2010 & & & 8 & & $51 \%$ & & \\
\hline Italy & 2010 & $2009^{1}$ & $2009^{18}$ & & & $50 \%$ & & \\
\hline Latvia & 2010 & $2010^{19}$ & 20 & & & $2 \%$ in 2010 & 39 & \\
\hline \multicolumn{8}{|l|}{ Lichtenstein } & \\
\hline Lithuania & 2011 & 20 & & & & $17 \%$ in 2010 & & \\
\hline Luxembourg & 2010 & $2010^{21}$ & & & & $64 \%$ & 204 & \\
\hline Malta & 2010 & 2010 & 2010 & & & $68 \%$ & 193 & \\
\hline Netherlands & 2010 & 22 & 2008 & & & $60 \%$ & & \\
\hline Norway & 2010 & 2010 & 2010 & & 9 & $57 \%$ & 309 & \\
\hline Poland & 2010 & 2010 & 23 & & & $8 \%$ in 2010 & & \\
\hline Portugal & 2010 & 2010 & 2009 & & & & 144 & \\
\hline Romania & 2011 & $2011^{24}$ & $2010^{25}$ & 26 & & & $53^{27}$ & \\
\hline Slovakia & 2010 & $2010^{28}$ & 2010 & 8 & 16 & $12 \%$ in 2010 & 19 & \\
\hline Slovenia & 2010 & 2010 & 2010 & 8 & & & & \\
\hline Spain & 2010 & 2009 & & & & & & \\
\hline Sweden & 2010 & $2008^{29}$ & 2008 & & & & 3 & \\
\hline Turkey & 2010 & 30 & & & & & & \\
\hline United Kingdom & 2010 & 2010 & 2010 & 8 & 31 & $56 \%$ in 2009 & & \\
\hline
\end{tabular}

ECDC: European Centre for Disease Prevention and Control; EEA: European Economic Area; EMCDDA: European Monitoring Centre for Drugs and Drug Addiction; EU: European Union; HIV: human immunodeficiency virus.

$\square$ No alert: no evidence for increased cases/prevalence and/or no evidence of low intervention coverage/no changes in surveillance

Alert: evidence for increased cases/prevalence and/or low intervention coverage/decreased surveillance

$\square$ Information unknown/not reported to EMCDDA/ECDC

1 HIV case increase taken from 2010 HIV surveillance data. Source: [15]. Bulgaria case report increased in 2008-2009, but returned to 2008 level in 2010. Case increases for Romania and Greece for 2011 were reported from country HIV surveillance and drugs focal points. Focal points from most other EU/EEA countries indicated no detected increase in new cases among IDUs in 2011 as compared to previous years.

2 For the purpose of this report a cut-off of $30 \%$ coverage was used in order to limit to the alert to the lowest range and likely highest HIV risk. Coverage levels below $50-70 \%$ of the target population are considered sub-optimal. Source: [7].

3 Syringes given out by specialised needle and syringe programmes, not including pharmacy sales. Source: [4].

4 Increases in Graz and Vienna, 2005-2010.

5 Based on the EMCDDA 2011 Annual report [9]: both Hungary and Austria reported notable increase of mephedrone injecting.

6 The ratio of HIV positive IDUs for the last 10 months (January to December 2011) increased with $8.9 \%$ in comparison with the whole 2010. The available data is for the capital city (Sofia) only.

7 Increase among all IDUs and among young IDUs, Sofia, 2005-2010.

8 Country experienced severe heroin shortage in 2010-2011 and reported on possible increased injecting risks for some groups.

9 IDU prevalence estimates (2010 data taken into account only for the Czech Republic and Greece).

${ }^{10}$ Increase among young IDUs 2004-2009 reported in the 2011 EMCDDA Annual report [9] is not continued in 2010.

${ }^{11}$ Increase in all IDUs 2005-2010.

12 Source: [3].

${ }_{13}$ Increase nationally and in Attica, Central Macedonia and Thessaly, 2005-2010.

${ }_{14}$ Reports of increased injecting of stimulants (home-made) at expert meeting Greece, October 2011 [3].

${ }_{15}$ National trend data until 2009 show no increase, data for 2010 show zero prevalence in six regions.

${ }^{16}$ Trend data available but not recent.

${ }_{17}$ Decline at national level, increase in one out of 21 regions (Veneto), 2004-2009.

${ }_{18}$ Decrease nationally, increasing trend in three out of the 21 regions (Abruzzo, Umbria, Valle d'Aosta), 2004-2009.

19 Increase in self-reported HIV prevalence 2004-2009 reported in the 2011 EMCDDA Annual report [9] is not continued in 2010.

${ }^{20}$ Varying prevalence in 2010 but no trend data available.

${ }^{21}$ Self-reported data; increase in 2010 reported [16].

${ }_{22}$ Zero prevalence in Amsterdam and Rotterdam 2010, but small sample sizes and no trends data.

${ }^{23}$ Varying prevalence in 2009 but no trend data available.

${ }^{24}$ Reported in the present paper.

${ }^{25}$ Increase 2005-2008 in all IDUs, and in male IDUs only in 2008-2010.

${ }^{26}$ Users switched to injecting amphetamine type stimulants (mostly mephedrone and other synthetic cathinones).

${ }^{27}$ Sub-national estimate, Bucharest area.

${ }_{28}^{28}$ Increase in HIV prevalence 2004-2009 reported in the 2011 EMCDDA Annual report [9] is not continued in 2010.

29 Trend data, available only until 2008 , suggest some non-significant increase.

${ }^{30}$ No trend data available, 2010 data suggest low prevalence.

${ }^{31}$ Injectors of opiates and/or crack-cocaine 
In Bulgaria, HIV case reports for IDUs increased by 8.9\% up to October 2011 in comparison with 2010, although 2011 data were only available for Sofia. At national level, an increase in the number of case reports for HIV among IDUs was already documented in 2009 in Bulgaria. In Luxembourg, drug surveillance data showed an increased HIV infection prevalence in current IDUs from $4.3 \%$ in 2009 to $8.1 \%$ in 2010 (no data available for 2011). However the proportion of all HIV cases who have injection drug use as a transmission route declined from $6.3 \%$ in 2010 to $3.6 \%$ in 2011 , as of November. In Italy, case reporting data for one region has increased, however the average national prevalence of HIV infection among IDUs continues to decline. Lithuania reported more than two times the number of HIV cases in 2009 and 2010 (180 and 153 respectively) as compared to 2008 ( 95 cases), but also reported increased testing among IDUs in 2010.

In addition to HIV case or prevalence increases, reports from some countries where data are available indicate a potential risk for HIV transmission in the IDU population with changes in drug use patterns, from mostly heroin in 2009 to more stimulant use in (Austria, Greece, Hungary, Romania); increased HCV rates among IDUs (Austria, Bulgaria, Cyprus, Greece, Italy, Romania); low coverage of opioid substitution treatment (Cyprus, Greece, Latvia, Lithuania, Poland, Slovakia) or low coverage of needle and syringe programmes (Croatia, Cyprus, Greece, Hungary, Latvia, Romania, Slovakia and Sweden).

\section{Discussion}

Overall, the incidence of HIV among IDUs in EU/EEA has been declining steadily since the early 2000 [ [15]. However, as a conclusion from the rapid risk assessment we note that two countries reported recent outbreaks of HIV, four countries reported increases in HIV cases or prevalence, and several other countries reported increases in injecting risk indicators (including HCV prevalence) or low coverage of prevention services among IDU. These factors combined indicate a potential risk for HIV transmission and future outbreaks.

There are clear indications of significant increased HIV transmission in Greece and Romania. While the magnitude of the most recent increases in case reports could be partially related to enhanced surveillance, particularly in Greece, the available evidence indicates a real increase in HIV transmission in both countries. In Romania, it is likely that a recent rise in the combined use of opioids and amphetamine-type stimulants resulting in increased injecting frequency could have contributed to HIV transmission. In both countries, there is a temporal association between this increase and reduced provision of prevention services (Romania) or initially low levels of) provision of prevention services (Greece). In Romania, these reductions have coincided with the end of a grant from the Global Fund for AIDS, tuberculosis and malaria in June of 2010.
The most robust and recent evidence suggests that the largest reduction of HIV and injection risk behaviour can be achieved by providing comprehensive prevention services, with high coverage of both needle and syringe programmes and opioid substitution treatment in combination $[17,18]$. In light of the growing prevalence of injection of amphetamine-type stimulants, as is reported in Romania, an additional and important challenge is to identify and implement effective treatment that targets this type of dependence $[5,9]$.

In order to prevent new outbreaks of HIV among IDUs, it is of utmost importance that countries that have indicated a change in injecting drug use risk factors or HIV and hepatitis C prevalence review their national or local prevention and control programmes in light of the current situation. Countries that experience ongoing increases or outbreaks would need to scale up their services urgently to prevent new cases. In the context of significant increased transmission of HIV among IDUs, rapid interventions in the form of scaling-up of needle and syringe programmes, provision of opioid substitution treatment and of condoms to reduce sexual HIV transmission are warranted.

The extent to which service reductions or changing patterns of risk among IDUs have been related to the current economic crisis in Europe cannot be easily measured and due to complex interactions between many factors, causal links are extremely difficult to establish. However, in past economic downturns, increased HIV incidence and increased injecting drug use have been observed $[19,20]$, and in a recent paper, Kentikelenis et al. have drawn links between the financial crisis in Greece and the increased HIV incidence [21]. In addition to exacerbating vulnerabilities and risk behaviours, economic downturns may also limit the funding available to prevention programmes [22]. The current outbreaks of HIV in IDUs in Greece and Romania show that there is a continuous need to keep prevention of HIV and public health on the agenda also in challenging economic times.

\section{Acknowledgments}

The authors wish to thank the national HIV surveillance and drug focal points who responded to the rapid request for information, in particular Drs. Adriana Pistol, Mariana Mardarescu, Florin Popovici, Argyro Antaraki and Manina Terzidou. Treatment and low-threshold services who provided the data are also acknowledged. Denis Coulombier, Katrin Leitmeyer, Emmanuel Robesyn, and Johan Giesecke provided important input.

\section{References}

1. European Centre for Disease Prevention and Control (ECDC), European Monitoring Centre for Drugs and Drug Addiction (EMCDDA). Prevention and control of infectious diseases among people who inject drugs. Stockholm: ECDC/EMCDDA; Oct 2011. Available from: http://www.ecdc.europa.eu/en/ publications/Publications/111012_Guidance_ECDC-EMCDDA. pdf 
2. Paraskevis D, Nikolopoulos G, Tsiara C, Paraskeva D, Antoniadou A, Lazanas M, et al. HIV-1 outbreak among injecting drug users in Greece, 2011: a preliminary report. Euro Surveill. 2011;16(36):pii=19962. Available from: http://www. eurosurveillance.org/ViewArticle.aspx?Articleld =19962

3. Malliori M, Terzidou M, Paraskevis D, Hatzakis A. HIV/AIDS among IDUs in Greece: report of a recent outbreak and initial response policies. [Accessed 29 Nov 2011]. Available from: http://www.emcdda.europa.eu/attachements.cfm/att_143752_ EN_HIV_greek_report.pdf

4. European Monitoring Centre for Drugs and Drug Addiction (EMCDDA). Statistical Bulletin 2011. Figure HSR-3. Syringes distributed through specialised programmes per estimated IDU in 2009 or more recent year. Lisbon: EMCDDA; 2011. [Accessed 29 Nov 2011]. Available from: http://www.emcdda.europa.eu/ stats11/hsrfig3

5. United Nations Office on Drugs and Crime (UNODC). HIV, HBV and HCV Behavioral Surveillance Survey among Injecting Drug Users in Bucharest, Romania. Bucharest: Speed Promotion; 2010.

6. Romanian National Antidrug Agency. National Report to the EMCDDA on the Drugs Situation in Romania, Bucharest. Bucharest: Romanian National Antidrug Agency; 2011.

7. European Monitoring Centre for Drugs and Drug Addiction (EMCDDA). Statistical Bulletin 2011. Figure HSR-1. Opioid substitution treatment clients as a percentage of the estimated number of problem opioid users, 2009 or most recent year available. Lisbon: EMCDDA; 2011. [Accessed 29 Nov 2011]. Available from: http://www.emcdda.europa.eu/stats11/hsrfig1

8. European Centre for Disease Prevention and Control (ECDC). Implementing the Dublin Declaration on Partnership to Fight HIV/AIDS in Europe and Central Asia: 2010 Progress Report. Stockholm: ECDC; 2010. [Accessed 29 Nov 2011] Available from: http://ecdc.europa.eu/en/publications/ Publications/1009_SPR_Dublin_declaration_progress_report. pdf

9. European Monitoring Centre for Drugs and Drug Addiction (EMCDDA). 2011 Annual report on the state of the drugs problem in Europe. Lisbon: EMCDDA; 2011. [Accessed 29 Nov 2011]. Available from: http://www.emcdda.europa.eu/ publications/annual-report/2011

10. Kivelä P, Krol A, Simola S, Vaattovaara M, Tuomola P, BrummerKorvenkontio $\mathrm{H}$, et al. HIV outbreak among injecting drug users in the Helsinki region: social and geographical pockets. Eur J Public Health. 2007;17(4):381-6.

11. Skar H, Sylvan S, Hansson HB, Gustavsson O, Boman H, Albert J, et al. Multiple HIV-1 introductions into the Swedish intravenous drug user population. Infect Genet Evol. 2008;8(5):545-52.

12. Caplinskiene I, Caplinskas S, Griskevicius A. [Narcotic abuse and HIV infection in prisons]. Medicina (Kaunas). 2003;39(8):797-803. Lithuanian.

13. Wiessing L, Likatavicius G, Hedrich D, Guarita B, Van de Laar $M$, Vicente J. Trends in HIV and hepatitis $C$ virus infections among injecting drug users in Europe, 2005 to 2010. Euro Surveill. 2011;16(48):pii=20031. Available from: http://www. eurosurveillance.org/ViewArticle.aspx?Articleld=20031

14. Rhodes T, Hedrich D. Harm reduction and the mainstream. In: Rhodes T, Hedrich D, editors. Harm Reduction: Evidence, impacts and challenges. Lisbon: EMCDDA; 2010.

15. European Centre for Disease Prevention and Control (ECDC)/ World Health Organization (WHO) Regional Office for Europe. HIV/AIDS Surveillance in Europe 2010. Stockholm: ECDC. 2011. [Accessed 29 Nov 2011]. Available from: http://ecdc.europa. eu/en/publications/Publications/111129_SUR_Annual_HIV_ Report.pdf

16. European Centre for Disease Prevention and Control (ECDC), European Monitoring Centre for Drugs and Drug Addiction (EMCDDA). Joint ECDC and EMCDDA rapid risk assessment: HIV in Injecting Drug Users in the EU, following a reported increase of cases in Romania and Greece. ECDC/EMCDDA; 2011. Restricted-access document.

17. European Centre for Disease Prevention and Control (ECDC), European Monitoring Centre for Drugs and Drug Addiction (EMCDDA). Evidence for the effectiveness of interventions to prevent infections among people who inject drugs. Part 1: Needle and syringe programmes and other interventions for preventing hepatitis C, HIV and injecting risk behaviour. Stockholm: ECDC/EMCDDA; 2011. [Accessed 29 Nov 2011]. Available from: http://ecdc.europa.eu/en/publications/ Publications/111129_TER_ECDC-EMCDDA_report_part1.pdf

18. European Centre for Disease Prevention and Control (ECDC), European Monitoring Centre for Drugs and Drug Addiction (EMCDDA). Evidence for the effectiveness of interventions to prevent infections among people who inject drugs. Part 2: Drug treatment for preventing hepatitis C, HIV and injecting risk behaviour. Stockholm: ECDC/EMCDDA; 2011. [Accessed 29 Nov
2011]. Available from: http://ecdc.europa.eu/en/publications/ Publications/111129_TER_ECDC-EMCDDA_part2.pdf

19. Suhrcke M, Stuckler D, Suk JE, Desai M, Senek M, McKee M, et al. The impact of economic crises on communicable disease transmission and control: a systematic review of the evidence. PLoS One. 2011;6(6):e20724.

20. Friedman SR, Rossi D, Braine N. Theorizing "Big Events" as a potential risk environment for drug use, drug-related harm and HIV epidemic outbreaks. Int J Drug Policy. 2009;20(3):283-91.

21. Kentikelenis A, Karanikolos M, Papanicolas I, Basu S, McKee $M$, Stuckler D. Health effects of financial crisis: omens of a Greek tragedy. Lancet. 2011;378(9801):1457-8.

22. Voelker R. One casualty of global economic crisis: uncertain finances for HIV/AIDS programs. JAMA. 2010;303(3):259-61 